\title{
Protected-Area Monitoring Dilemmas: a New Tool to Assess Success
}

\author{
KENDRA L. WALKER \\ University of Michigan School of Natural Resources \& Environment, Dana Building, 440 Church Street, Ann Arbor, \\ MI 48109-1041, U.S.A., email klwalker@umich.edu
}

\begin{abstract}
Understanding factors that influence the success of protected areas in curbing unsustainable resource consumption is essential for determining best management strategies and allocating limited resources to those projects most likely to succeed. I used a law-enforcement and monitoring game-theory model from the political science literature to identify three key variables useful in predicting the success of a protected area: costs of monitoring for rule breakers, benefits of catching a rule breaker, and probability of catching a rule breaker if monitoring. Although assigning exact values for each of these variables was difficult, the variables had a strong predictive capacity even when coded as coarse ordinal values. A model in which such values were used correctly predicted the outcome of 88 of 116 protected areas sampled from the peer-reviewed literature. The model identified a critical zone of common mismatch between protected-area circumstances and management policies. In situations where the costs of monitoring were greater than the product of the probability of catching a rule breaker and the benefit of doing so, conservation was unlikely to succeed. Control of illegal use of protected resources was reported in only $8 \%$ of such cases, regardless of strategies to motivate potential users to cooperate with conservation. My model does not prescribe a best management policy for conserving natural resources; rather, it can be used as a tool to belp predict whether a proposed management policy will likely succeed in a given situation.
\end{abstract}

Keywords: community-based conservation, game theory, monitoring, national parks, protected areas, rule enforcement

Dilemas del Monitoreo de Áreas Protegidas: Una Herramienta Nueva para Evaluar el Éxito

Resumen: El entendimiento de los factores que influyen en el éxito de las áreas protegidas para controlar el consumo no sustentable de los recursos es esencial para la determinación de las mejores estrategias de manejo y asignar recursos limitados a los proyectos con mayor probabilidad de éxito. Utilicé un modelo de aplicación de leyes y teoría de juegos tomado de la literatura de ciencia política para identificar tres variables claves útiles para pronosticar el éxito de un área protegida: costos de monitoreo para infractores, beneficios por la captura de un infractor y la probabilidad de atrapar a un infractor si bay monitoreo. Aunque la asignación de valores exactos para cada una de esas variables fue difícil, las variables tenían una alta capacidad pronosticadora aun cuando fueron codificadas con valores ordinales crudos. Un modelo en que se usaron tales valores pronosticó correctamente el resultados de 88 de 116 áreas protegidas muestreadas en la literatura. El modelo identificó una zona crítica de incompatibilidad entre circunstancias del área protegida y políticas de manejo. En situaciones en que los costos de monitoreo fueron mayores que el producto de la probabilidad de atrapar a un infractor y el beneficio de hacerlo, era poco probable que la conservación tuviera éxito. El control del uso ilegal de recursos protegidos fue reportado en solo $8 \%$ de esos casos, no obstante las estrategias para motivar a los usuarios potenciales a cooperar con la conservación. Mi modelo no prescribe una política de mejor manejo para la conservación de recursos naturales; sino más bien puede ser utilizada como una berramienta para ayudar a pronosticar sí una política de manejo propuesta tendrá éxito en una situación determinada. 
Palabras Clave: aplicación de reglas, áreas protegidas, conservación basada en comunidades, monitoreo, parques nacionales, teoría de juegos

\section{Introduction}

It is increasingly clear that there is no panacea to solving conservation dilemmas (Ostrom \& Nagendra 2006). Although government and internationally managed protected areas have been successful in conserving natural resources in some cases (e.g., Bruner et al. 2001; WWF 2004; Nagendra 2008) and local management institutions have demonstrated success in other cases (Hayes \& Ostrom 2005; Hayes 2006), both have failed to protect resources in many cases. Debates over the one right strategy to conservation are futile because social systems are complex (Agrawal \& Gibson 2001), ecological systems are complex (Costanza \& Ruth 2001), and humanecological systems are especially complex (Berkes et al. 2003; Berkes 2006). Why, then, should there be a single blueprint for solving all of the world's conservation dilemmas?

Despite the growing body of literature on the diversity and complexity of human-ecological systems, protectedarea managers and funding organizations still tend to favor extremely simplistic blueprints for conservation management. The problem is not likely lack of knowledge or foresight regarding the complexity of conservation problems as much as an issue of advocacy and policy making (Borgerhoff Mulder 2007). Writing about the complexity of problems is much easier than addressing complex problems; to address such problems, policy makers need clearly defined strategies. Although there is increasing demand for detailed conservation management plans (Hockings 2003) and upfront cost analyses to avoid sinking resources into hopeless projects (Naidoo et al. 2006), the tools to help diagnose appropriate strategies under limited time and budgetary constraints are lacking (Ferraro \& Pattanayak 2006). Compared with tools for assessing biological components, those for assessing social factors affecting the success of protected areas are especially scarce, despite the fact that it is the human impact on the resources that typically determines the success or failure of a protected area.

Models can be powerful tools with which policy makers can avoid exhausting resources on inappropriate strategies. Yet models lose their practicality when they are complex and when the initial investment required is high. The handful of preliminary models available in the current literature, although insightful and impressive, would likely overwhelm a project manager trying to decide the best immediate course of action. For example, Agrawal and Chhatre (2006) identify over 30 variables significant to conservation outcomes, Ostrom (2007) and Brooks et al. (2006) add many questions to the manager's research agenda, and Chhatre and Agrawal (2008) highlight the need to look at context and interaction effects. Although all of these considerations are likely pertinent for determining the ideal strategy for a specific situation, the resources required to answer all questions may be prohibitive.

Here, I present some relatively simple variables that perform well in identifying the most common mismatches between protected-areas circumstances and management strategies. Although by no means all inclusive, these variables should be minimal requirements for any precursory assessment or justification of a protectedarea management plan. I derived these variables from work predominantly in the commons literature, but they are applicable to all conservation strategies. I considered only protected-area management, which I define as situations in which the state owns the resource in question and manages it primarily from the top down. Such management can occur with varying degrees of community involvement and compensation and is thus often presented in conservation literature as "community-based" conservation. The key distinction between situations of protected-area management, by my definition, and most conservation situations presented in the commons literature is that the primary initiator and rule-making institution is the state (or a third party acting on behalf of the state) rather than the user group itself.

Although I focused on management of protected areas, my goal was not to argue that protected areas are the only way to conserve resources. Local rule-making institutions can be equally or more effective than top-down management in many situations (Hayes \& Ostrom 2005). However, successful local institutions are generally selfemergent and deep rooted (Stern et al. 2002). There are many situations in which local institutions may not exist or readily evolve at critical conservation moments and in which top-down initiation might be the more plausible strategy. It is much harder for a policy maker to create a situation in which conservation attitudes and rules emerge from the community itself than to impose conservation rules from outside that nonetheless benefit the community (and thus may eventually take root in the community and evolve into local management). My goal was not to prescribe a "best" management policy for conserving natural resources, but rather to provide tools to help predict whether a proposed management policy will be likely to succeed in a given situation. 


\section{Methods}

\section{Model of the Monitoring Dilemma}

The key variables I used (Table 1) are drawn from a game-theory model of monitoring and rule enforcement presented in the political science literature as early as 1989 (Tsebelis 1989) that has since been represented in various forms in the political science and commons literature (Holler 1991; Ostrom et al. 1994; Weissing \& Ostrom 2000). This model can get quite complicated and lead to surprising results at states of mixed equilibria; however, the variables of interest were derived from the simplest equilibrium points of the model. For this reason, only the most basic foundations of the model are described here. For a discussion of the model in more complex states, see Weissing and Ostrom (2000). Understanding of the full-fleshed model is essential for evaluating outcomes of most common pool-management situations; however, my results show that such understanding is less necessary for predicting the outcome of most typical situations in protected-area management.

The importance of law enforcement and monitoring in the successful management of protected areas has been underscored throughout the conservation literature (Leader-Williams \& Milner-Gulland 1993; Gibson et al. 2005; Dobson \& Lynes 2008). Many empirical studies have found monitoring and rule enforcement to be more strongly correlated with resource condition than any other variable, in both local management and top-down management situations (e.g., Bruner et al. 2001; WWF 2004; Gibson et al. 2005). Given that effective monitoring is clearly a good predictor of the success of a protected

Table 1. Variables relevant to monitoring dilemma model to predict success in protected-area management.

\begin{tabular}{|c|c|c|}
\hline Variable & Definition & $\begin{array}{l}\text { Coding } \\
\text { scheme }\end{array}$ \\
\hline \multicolumn{3}{|c|}{ Independent } \\
\hline$B_{m}$ & benefit or value of resource to monitor & 1 to 5 \\
\hline$B_{u}$ & benefit or value of resource to user & 0 to 5 \\
\hline$C$ & cost of monitoring & 1 to 5 \\
\hline$P$ & $\begin{array}{l}\text { probability a monitor will catch an } \\
\text { illegal user }\end{array}$ & 1 to 5 \\
\hline$M$ & $\begin{array}{l}\text { income gained by monitor for catching } \\
\text { illegal user }\end{array}$ & 0 to 3 \\
\hline$F^{b}$ & $\begin{array}{l}\text { cost of punishment to illegal user (if } \\
\text { caught) }\end{array}$ & 1 to 5 \\
\hline \multicolumn{3}{|c|}{ Dependent } \\
\hline$O_{m}$ & $\begin{array}{l}\text { monitoring outcome (does monitoring } \\
\text { occur?) }\end{array}$ & 0 or 1 \\
\hline$O_{u}$ & $\begin{array}{l}\text { user outcome (is illegal use effectively } \\
\text { reduced?) }\end{array}$ & 0 or 1 \\
\hline
\end{tabular}

$\overline{{ }^{a} \text { Details of attribute levels are available (see Supporting Informa- }}$ tion).

${ }^{b}$ Not relevant to the first or second node, thus not essential for this study. area, predicting whether managers will invest in effective monitoring is critical.

As various versions of the monitoring game (Tsebelis 1989; Mesterton-Gibbons \& Milner-Gulland 1998; Weissing \& Ostrom 2000) demonstrate, not all situations are conducive to effective monitoring. In fact, successful monitoring is only expected to result from a very limited set of conditions. By deriving the set of conditions that predict whether effective monitoring and rule enforcement is likely to occur, my model yields powerful hypotheses regarding the predicted success of different conservation situations.

The monitoring dilemma is set up as a game with two players, resource users and managers, in which each player has two options per turn. The resource user must decide whether to abide by the law or to illegally use a protected resource, and the manager must decide whether or not to monitor for illegal activity. By dissecting the game diagram (Fig. 1), I constructed a predictive flow chart in which complexity in predicting the outcome increases at each node (Fig. 2). By beginning with

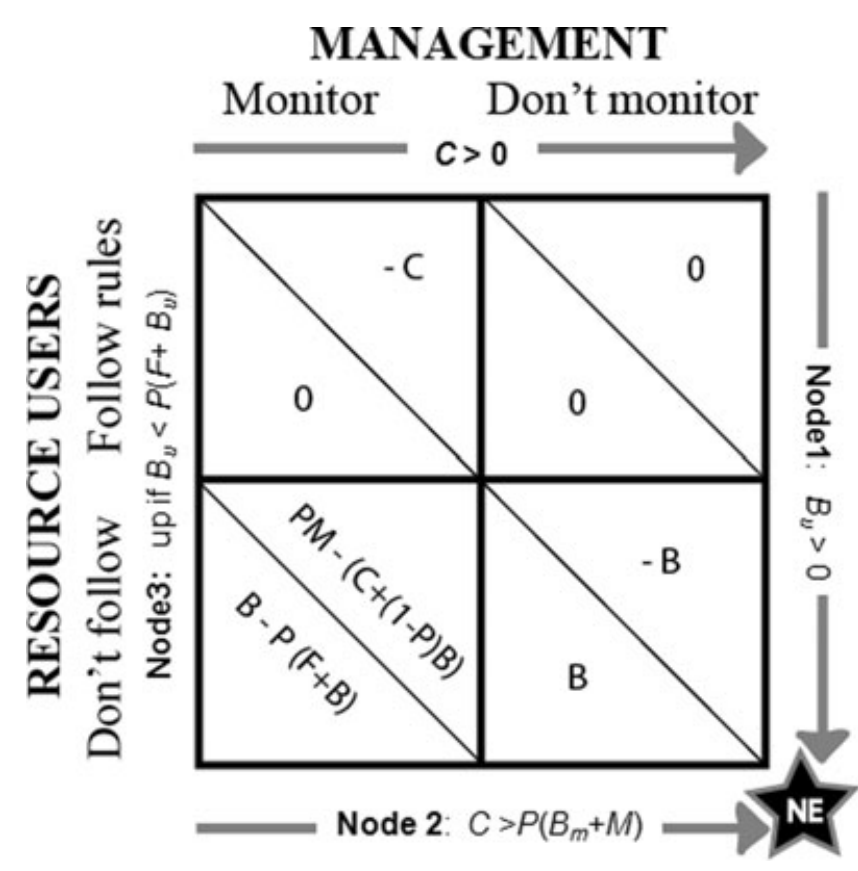

Figure 1. The general conditions of the monitoring dilemma as presented by Ostrom et al. (1994). Situations are in order of easiest to most difficult to predict (node 1, managers not monitoring, thus users expected not to follow rules protecting the resource so long as they derive benefits from using the resource; node 2, users not following rules and probability of catching a rule breaker times the benefit to the monitor of doing so is less than the cost of monitoring, thus monitors not expected to monitor; NE, Nash equilibrium; variable definitions are provided in Table 1). 


\section{Node 1}

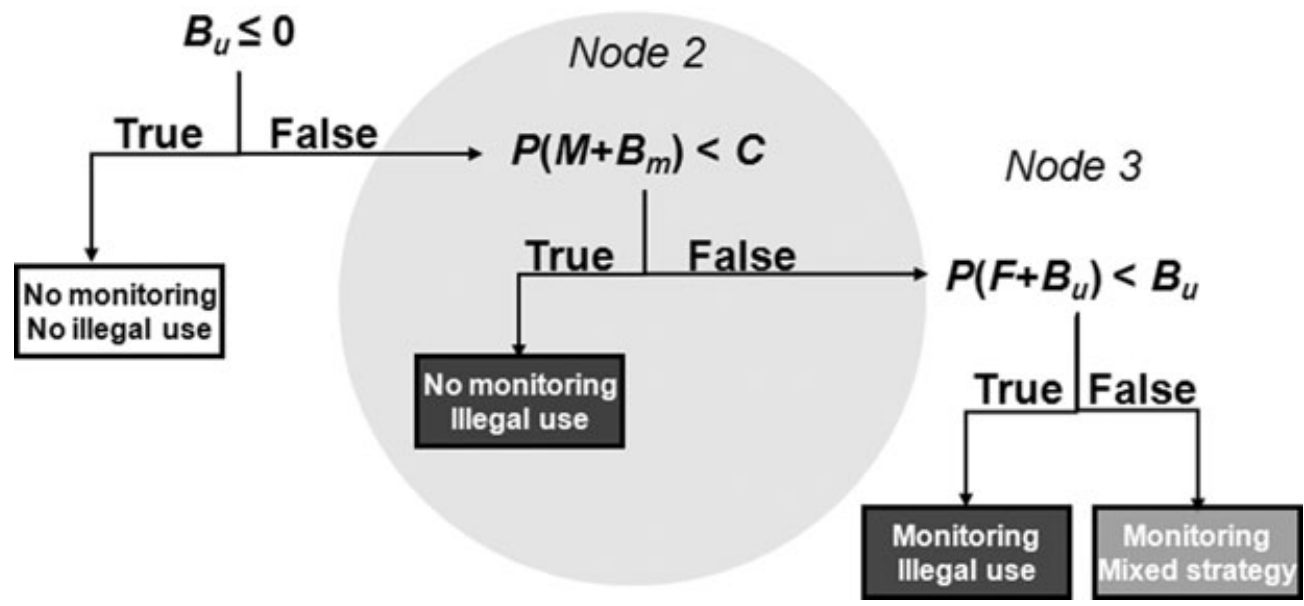

Figure 2. Flowchart for predicting the outcome of a monitoring dilemma game presented in Fig. 1, ordered from easiest to most difficult to predict: node 1, benefit of using the resource $\leq 0$ for the potential users, thus resource is not exploited illegally regardless of the presence of monitors; node 2, users derive benefit from using the resource and the probability of catching an illegal user times the benefit of doing so is less than the costs of monitoring, thus monitors elect not to monitor and illegal use of the resource continues (gray circle, area of many mismatches between protected-area circumstances and management strategies); node 3, monitors are monitoring, but probability of being caught times the consequences is less than the benefits a user derives from exploiting the resource, thus illegal use continues despite the presence of monitors; opposite of node 3 is true, mixed-strategy equilibrium with reduced resource exploitation expected. Variables are defined in Table 1.

the simplest prediction (the first node) and working toward the much more complex questions (the third node and beyond), most protected-area policy mismatches can be identified early on and with minimal investment of resources.

\section{Node 1: Is the Resource Disputed?}

The first node identifies whether the management situation poses any dilemma between a user group and the management agency. Dilemmas arise when the use of a resource is disputed, which occurs only when the user associates a positive benefit $\left(B_{u}\right)$ with using the resource. Situations do occasionally appear in the literature where the potential resource user associates no benefit, or even associates a cost, with using the protected resource regardless of rules. In such cases $B_{u} \leq 0$, and one would expect to see cooperation with conservation efforts because there is no reason not to cooperate. In true resource dilemmas, however, $B_{u}>0$ and resource users are expected to continue using the resource unless there are negative consequences for doing so. If there is no monitoring to catch rule breakers, a user will choose to use the protected resource regardless of laws (Fig. 1, arrow for node 1 points down). The eventual degradation of the resource is obviously a negative consequence, but factors external to the individual are necessary to encourage users to cooperate with rules instead of acting to maximize only their own immediate gains.
Node 2: Is Monitoring Worthwhile from the Monitor's Perspective?

The most common strategy for overcoming degradation of resources due to collective action dilemmas is to create rules and negative consequences for breaking those rules. Because consequences are not possible without enforcement and enforcement is not possible without monitoring, rules require monitors. The addition of rules adds this new player, the monitor, to the game. One must first overcome the monitoring dilemma before the original dilemma can be resolved.

The first part of the monitoring matrix is given. Because there is always a cost $(C)$ involved with monitoring, managers would prefer not to monitor if they expect potential resource users to abide by their rules anyway (Fig. 1, top arrow points right). Resource users will use the resource regardless of rules if they expect no monitoring to occur, and monitors will not monitor if they expect users to not use the resource anyway. Because both parties are aware of this situation, the more insightful questions are what are monitors expected to do when they expect users will illegally use the protected resource and what are resource users expected to do when they expect monitoring to occur. These questions, represented by the remaining two sides of the monitoring dilemma matrix (Fig. 1), shape the likelihood of successful management interventions.

The first question, regarding the monitor's actions, encompasses node 2 (Fig. 2) because it requires fewer 
variables than the second question to predict. If managers do not monitor while users continue to use the resource, they suffer losses $\left(-B_{m}\right)$ equivalent to the lost resource. If managers do monitor and catch a user not abiding by the rules, managers gain both the corresponding benefits of the resource in the form consumed by the user $\left(B_{u}\right)$ and any additional revenues $(M)$ from fines imposed on the offender. It is not always the case, however, that the monitors will catch offenders. The probability $(P)$ of catching rule breakers must be taken into consideration. The resulting equation for calculating the expected payoff of monitoring is $P(M-C)-(1-P)(-B-C)$ (Fig. 1). When this is greater than $-B_{m}$, the expected payoff of not monitoring, managers will choose to monitor. Although fairly intuitive, the reduced form of this equation, $P(M+$ $\left.B_{m}\right)>C$, reveals much about the management strategy for protected areas. Only if the probability of catching a rule breaker times the benefit of doing so is greater than the cost of monitoring will managers elect to monitor, even if they suspect their rules are not being followed (Fig. 1, arrow for node 2 points left).

Monitors' interests are oversimplified here. In reality, individual monitors are rarely rewarded the entire fine imposed on the offender, and they usually do not benefit entirely from $B_{u}$ (especially if they effectively preempt extraction of the resource). Although the benefits of monitoring are spread across the entire community or managing agency, monitors bear the full costs individually. An extensive literature is devoted to such second-order collective action dilemmas (Oliver 1980) and the factors that help or hinder groups in overcoming them (Boyd \& Richerson 1992; Agrawal \& Goyal 2001; Kiyonari \& Barclay 2008). Fine-tuning of the model requires consideration of such second-order factors; however, measuring them can be difficult. Because $M, B_{u}$, and $B_{m}$ are assigned coarse ordinal values in my model, they can be considered proxies for the relative proportion of the benefits the monitor receives and can thus carry valuable information without requiring precise data.

\section{Node 3: Is Using the Resource Worthwhile from the User's Perspective?}

As with higher-order dilemmas, the third node (Fig. 2, left side of Fig. 1) involves a complex set of variables. This node regards the user's actions when she or he expects the monitor to be monitoring (in other words, when $P[M$ $\left.+B_{m}\right]>C$; arrow in Fig. 1, node 2 points left). The model is taken to completion in Weissing and Ostrom (2000) and predicts that the resource user will use the resource illegally even when she or he expects monitoring to occur if the benefit to the user, $B_{u}$, is greater than the probability of getting caught times the sum of $B_{u}$ and the expected punishment $(F)$ (Fig. 1, node 3 arrow would point down). If the opposite is true (node 3 arrow points up), there is a mixed strategy equilibrium with some mon- itoring and reduction, but not elimination, of illegal use of the resource. Understanding the nuances of this condition is useful for making predictions at the third node and is the subject of much discussion in the commons literature. This state is not elaborated upon here, however, because it involves complex variables that are difficult to assess in the field. In contrast, the variables of the second node are relatively easy to predict and may yield the greatest insight into typical protected-area-management mismatches.

\section{Typical Strategies for Overcoming Conservation Dilemmas}

There is ongoing debate in the conservation literature regarding whether increasing the benefits of conservation to the local community or increasing punishment for rule breaking is the most effective tactic for protectedarea management. My monitoring model suggests that neither tactic is effective in most typical protected-area situations. In most situations, the variables driving the monitor's decision are those that determine the outcome because the resource users make their decision according to what they think the monitors will do.

By my definition protected-area management implements a top-down approach, where a third-party entity detached from the user community establishes rules and takes responsibility for enforcing those rules. In cases where local communities continue to use the resource in a protected area despite the rules, protected-area managers typically resort to one of the following general strategies: create more disincentives for rule breaking by establishing even harsher rules (stick); provide more benefits to the user community to create incentives for cooperation with laws (carrot); or devolve monitoring responsibilities (and costs) to the user community (pass the buck).

If the failure of the initial strategy occurs on the monitor's side of the model, however, stick and carrot strategies will likely have no influence on the conservation outcome because these strategies act on the incentives of the resource user and not those of the monitor. A strategy devised to overcome failure at node 2 of a protectedarea situation can only result in better protection of the resource if it acts on one of the variables $C, P, M$, or $B_{m}$, sufficiently enough to reverse the equation $P\left(M+B_{m}\right)<$ $C$. Although incentives and disincentives can significantly affect variables on the user's side, such as $F$, this variable is not relevant until node 3 . If the case fails at node 2 (the monitor is not expected to monitor) the resource user is not expected to change his or her behavior because there is no increase in actual risk if there is no monitoring.

Devolving monitoring costs to the user community (pass the buck) can be an effective strategy with which to overcome a second-node failure because this change acts directly on variables on the monitoring side. The probability of catching rule breakers can be maximized 
while minimizing costs of monitoring if people can monitor while going about their normal routines. Again, this strategy is predicted to work only if it results in a reversal of the equation $P\left(M+B_{m}\right)<C$, so that monitors would be expected to monitor. Cases in which monitoring responsibilities and rule-making responsibilities (including choice of whether to protect the resource at all) are effectively transferred to the user community do not fall within my definition of protected-area management situations and are thus outside the scope of this analysis.

\section{Summary of Model Predictions}

Based on the monitoring dilemma model described above, I generated a series of predictions regarding the potential success of a given protection strategy under different circumstances. A flowchart depiction of these model predictions is presented in Fig. 2 and the variables are summarized in Table 1 . The nodes are defined as follows:

- Node 1 , if the benefit of using the resource is zero or less $\left(B_{u} \leq 0\right)$, the user is expected to cooperate with rules.

- Node 2 , if the probability of catching a rule breaker times the benefit of doing so is less than the cost of monitoring, $P\left(M+B_{m}\right)<C$, monitors are not expected to monitor and users will continue to illegally use the resource.

- Node 3 , if the probability of catching a rule breaker times the benefit of doing so is greater than the cost of monitoring, $P\left(M+B_{m}\right)>C$, mixed results are expected that will significantly differ from those of nodes 1 and 2. More successful outcomes are expected here compared with node 2 , but specific results depend on factors beyond this model.

The above hypotheses should hold true regardless of the strategy used (neutral top-down monitoring, topdown monitoring with carrot, top-down monitoring with stick, pass the buck). However, a pass-the-buck strategy is more likely to result in a situation in which $P\left(M+B_{m}\right)$ $>C$.

\section{Applying the Model to Protected-Area Cases}

Assigning precise values to variables $P, M, B_{m}$, and $C$ is difficult, even for a manager who is very familiar with the situation of a given protected area. To simplify the task, I developed an ordinal ranking scheme for assigning each of the variables a value of $1-5$ based on basic observations of the protected area and the nature of the resource type and restriction in question (see Supporting Information). Because the use of ordinal numbers compromises the integrity of the original mathematical model (one cannot assume that one unit of $B$ equals one unit of $C$, for example), I rebalanced the model by adding weighting coefficients to each variable and optimizing them with a training set of 50 cases from current peer-reviewed literature. I used an additional 66 cases to validate the resulting model.

I selected model training and validation cases by searching the ISI Web of Knowledge for combinations of key phrases: community ${ }^{*}$, natural resource management, conservation, protected are $a^{*}$, reserve $^{*}$, and national park* ${ }^{*}$. The definition of protected area was extended to apply to both geographical entities (areas of land or water) and conceptual entities (e.g., wildlife or fish). Cases regarding situations in which communities have initiated and historically managed their own conservation efforts were not reviewed because such situations commonly differ in many ways from the typical protected-area management cases for which this model was proposed. If pertinent information regarding one or more of the variables in Table 1 was missing, I performed another search on the protected area in question and examined up to five of the most recent peer-reviewed manuscripts to fill in the gaps. I also used some nonpeer-reviewed sources (World Center for Monitoring of Conservation, ParksWatch, United Nations Educational, Scientific \& Cultural Organization [UNESCO]) to inform background details such as park area and number of enforcement personnel. Cases and data sources are available (see Supporting Information).

I coded outcome as a binary variable ("substantial illegal use" or "general cooperation with rules") despite the fact that some level of illegal resource use almost always persists. Even if a minimum level of illegal use was reported, I considered resource protection successful if authors reported significant reduction in resource use from preprotection levels or greater abundance or quality compared with nearby, comparable, unprotected resources.

The model was optimized with evolutionary search methods to determine the set of weighting coefficients that best minimized the squared error between the training set observations and the model predictions. I used Frontline Systems Premium Solver 8.0 in Microsoft Excel to perform the evolutionary searches. I ran 50 initial parameter configurations 5 times each at 1000 iterations and selected the top 25 models as candidates for testing with the validation set. The variance in the results between candidate models was calculated to gauge the sensitivity of the model to different weighting configurations.

\section{Results}

The literature sampling resulted in 116 cases from 35 countries spanning all continents except Antarctica. Cooperation with the conservation rule was reported in $46 \%$ of cases, whereas substantial illegal use of the resource was reported in $54 \%$ of cases (Fig. 3). 


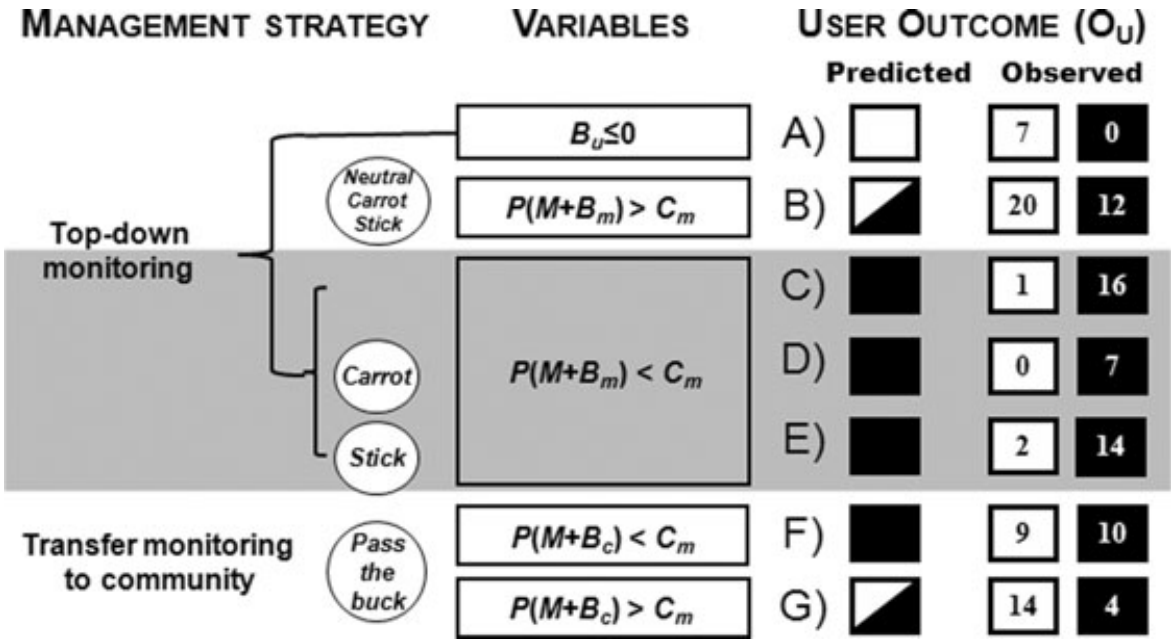

Figure 3. Performance of the monitoring model in predicting case-study outcomes: black boxes, substantial illegal use of the protected resource; white boxes, general cooperation with protection rules; black and white boxes, mixed predictions; numbers correspond to the number of literature cases reviewed with outcomes falling under each category. Gray rectangle bighlights node 2 , where most management mismatches occur. Letter variables are defined in Table 1.
The best-fit model for the training set was $0.93 P^{*}(4.6 M$ $+3.1 B) / 3.6 C$, and its error was 0.24 . Surprisingly, the default model, $1 P^{*}(1 M+1 B) / 1 C$ performed almost equally well (error of 0.26 ) and outperformed the best-fit model on the validation set (errors of 0.24 and 0.25 , respectively). For the sake of creating a user-friendly tool, I retained the simpler default model as the final model. All results reported here thus apply to the model in which $P, M, B$, and $C$ each has a weight of one.

Overall, the model prediction and the reported outcome matched for $76 \%$ of cases. The predictive capacity of the model was much stronger for some combinations of management strategy and variables than others (Fig. 3). The model proved a strong predictor for category A, corresponding to node one, where its prediction of cooperation with conservation rules was accurate for all 7 cases. Under top-down management, in which monitoring is entirely the responsibility of someone outside the user community, the model also showed strong predictive capacity when $P\left(M+B_{m}\right)<C$ (categories $\mathrm{C}, \mathrm{D}$, and $\left.\mathrm{E}\right)$, but weak predictive capacity when $P\left(M+B_{m}\right)>C$ (category B). Cooperation with conservation rules was evident in only $3(8 \%)$ of the 37 cases in which $P\left(M+B_{m}\right)<C$, but was evident in $20(62 \%)$ of the 32 cases in which $P(M+$ $\left.B_{m}\right)>C$.

Under decentralized monitoring, in which some level of monitoring responsibility is passed down to the user community, the model proved a weak predictor when $P\left(M+B_{m}\right)<\mathrm{C}$ (category $\left.\mathrm{F}\right)$, but was a strong predictor when $P\left(M+B_{m}\right)>C$ (category $G$ ). Benefits of monitoring were estimated to outweigh costs for 32 (44\%) of the 72 cases involving top-down monitoring, compared with 18 (49\%) of the 37 cases involving pass-the-buck strategies.

Categorization of cases, and thus predicted outcomes, did show some sensitivity to choice between the different weighting schemes of the 25 best-fit models. As the bal- ance of $P\left(M+B_{m}\right)$ relative to $C$ changed, some cases in categories C, D, and E switched to category B (depending on whether the management strategy was neutral, carrot, or stick, respectively) and vice versa, and cases in category $F$ switched to $G$ and vice versa (Fig. 4). Cases in category A did not change because they were determined by the single variable $B_{u}$. Despite this sensitivity to model choice, the difference in outcomes remained significant for all categories except $F$ regardless of the best-fit candidate model chosen (Student's $t$ test, $p=0.95$ for category $\mathrm{F}, p<0.01$ for all others).

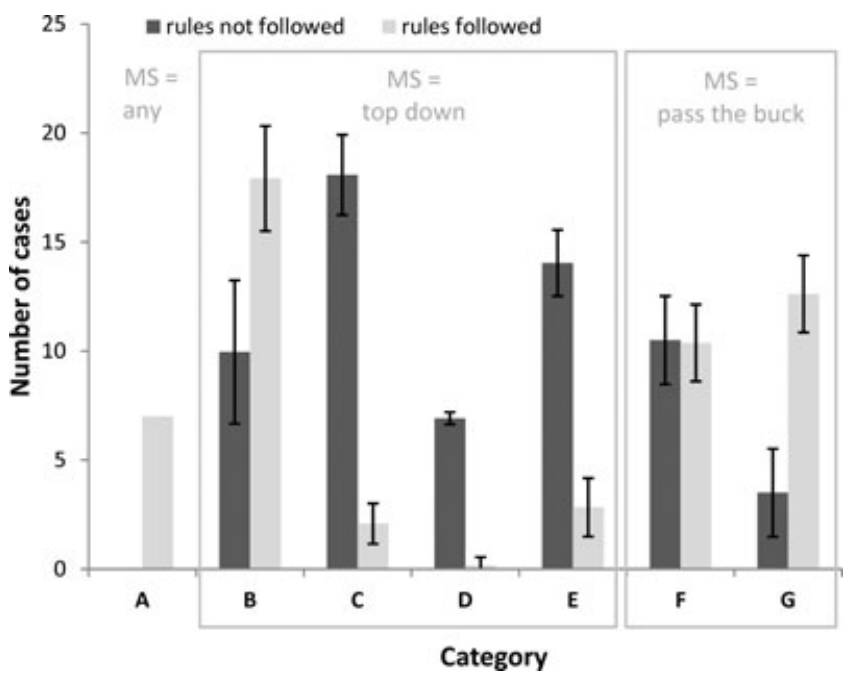

Figure 4. Number of protected-area cases from the literature falling into each of the seven categories of the monitoring dilemma model (MS, general management strategy; categories A-G in Fig. 2; light gray, successful cases; dark gray, unsuccessful cases; error bars, SD in case placement between the 25 best-fit models). 


\section{Discussion}

The results of the monitoring model applied to case studies in the literature highlight a critical area of mismatch between typical protected-area circumstances and management strategies. Top-down protected-area management and monitoring most often results in a scenario in which the costs of monitoring for rule breakers outweigh the probability of catching a rule breaker multiplied by the benefits of doing so. When this is the case, monitoring is generally sporadic at best, and illegal resource use is usually common. To curb this illegal use, managers often turn to carrot or stick strategies to convince potential users to cooperate with rules by raising incentives for cooperation or increasing punishment for rule breaking. However, when the failure occurs at node 2 (the monitor's side of the game), these strategies will have little effect in curbing resource use because illegal users do not expect to get caught. That $92 \%$ of reviewed cases failing at node 2 were not successful in curbing illegal resource use regardless of whether neutral, carrot, or stick strategies were applied (Fig. 3, categories C, D, and $\mathrm{E})$ should alert managers to the mismatch in such strategies.

Although my results demonstrate that carrot strategies of increasing benefits of conservation are not effective in curtailing illegal resource use in the short term, this is not to say there is no benefit in such strategies. Local communities often bear the brunt of the costs of conservation and deserve to gain something in return for moral reasons if nothing else. For effective conservation, carrot strategies could be most successful if involving the user community in conservation efforts is seen as a longterm investment, with the ultimate goal of turning over conservation management and responsibilities entirely to the community (i.e., pass the buck and eventually complete devolution). Such devolution can greatly reduce management costs, potentially reversing the balance of monitoring costs to benefits to favor true monitoring. In this study, pass-the-buck strategies showed only slightly greater tendency to result in situations favoring monitoring (where $P\left[M+B_{m}\right]>C$ ) than top-down strategies ( $44 \%$ and $49 \%$ of cases, respectively). Projects initiated by the community, however, were excluded from the sample, and inclusion of such projects might result in a greater difference.

The weakest predictive area of this model was when $P\left(M+B_{m}\right)>C$ (Fig. 3, category B). The mixed results within this category are expected because it occurs at the third node, involving factors beyond those of this study and whose dynamics often yield situations of mixed-state equilibria. It is also possible that prediction capacity of this category is weakened by erroneous placement of some cases due to over- or underestimation of one or more of the variables such that the balance between
$P\left(M+B_{m}\right)$ and $C$ is altered. Here, $M$ and $B_{m}$ are especially susceptible to overestimation due to the assumption of a linear relationship between the monitor's benefits and the total value of the resource. In reality, an agency may receive a high $\boldsymbol{B}_{m}$ payoff from tourism or carbon credits, for example, or a large $M$ payoff by confiscating valuable assets, but may not share much of the benefits with individual monitors. Monitors who do not receive the benefits personally have little incentive to monitor regardless of the total value to the agency. Alternatively, monitors may receive high benefits from bribes, giving them incentive to allow illegal use to continue. To better predict outcome in this category, more information on monitor accountability and incentive schemes would be useful. Unfortunately, such data are rarely presented in the literature and thus could not be examined here.

As with the top-down strategy in which $P\left(M+B_{m}\right)>$ $C$ (Fig. 3, category B), a pass-the-buck strategy in which $P\left(M+B_{m}\right)>C$ (Fig. 3, category G) was expected to produce mixed results. However, illegal resource use was reported in noticeably fewer cases for the pass-the-buck strategy ( $22 \%$ for category G vs. $38 \%$ for category B). Likewise, although a pass-the-buck strategy in which $P(M+$ $B_{m}$ ) $<C$ (Fig. 3, category F) was expected to be as ineffective as a top-down strategy with the same unfavorable cost-benefit balance (Fig. 3, categories C, D, and E), $47 \%$ of cases reported success in reducing illegal resource use in category $\mathrm{F}$, compared with a mere $8 \%$ of cases in categories C, D, and E. The higher success of pass-the-buck cases may reflect incentives not well accounted for in this model, such as social currencies. For such cases involving community-based monitoring, even at the incomplete level of devolution considered in this model, the more intricate community-level monitoring models of Mesterton-Gibbons and Milner-Gulland (1998) and common-management variables such as those identified by Agrawal and Chhatre (2006) may yield more insight.

Although it is plausible that important variables were overlooked, it is also possible that authors writing about community-based monitoring have a greater tendency to publish successful cases than those writing about topdown management. Published literature provides an inherently biased representation of real-world practices, and caution should be taken in using this medium to gauge the frequency of different management strategies. Such case studies are more useful in providing insight into the effectiveness of a particular strategy than comparing results between strategies. Even then, different authors likely perceive and report situations differently, toning down aspects that others might exaggerate or vice versa. Assigning specific values to such written information involves some degree of subjectivity. Due to variance in author perception, writing style and coder interpretation, it is unlikely that a perfectly predictive model could be 
constructed based on published literature alone. Given such subjectivity, the predictive capacity of this model in categories $\mathrm{C}, \mathrm{D}$, and $\mathrm{E}$ is striking.

This model demonstrates that a majority of the failed cases presented in the current conservation literature can be explained by the monitoring-side predictions of the monitoring dilemma. Managers of protected areas, especially those monitored from the top-down, would greatly benefit from incorporating this tool into current management-plan assessments and evaluation protocols to determine the likely success of current or proposed management strategies.

Protected areas are increasingly expensive to monitor and enforce (Hayes \& Ostrom 2005). Although management costs are increasing, international financing of protected areas appears to have reached a plateau (Molnar et al. 2004). Mean expenditure for protected areas in developing countries is estimated between $\$ 93$ and $\$ 157 / \mathrm{km}^{2}$, whereas estimates for effective management indicate that at least $\$ 277$ is needed for each square kilometer protected in developing countries (James et al. 2001). With such limited funds and so much area worthy of protection, it is critical to assess the potential of a given management strategy to succeed before investing too much money in that strategy. This tool can help managers inexpensively identify the most prominent mismatches. The saved resources could be invested into project evaluation so as to provide feedback for future tuning of this tool.

\section{Acknowledgments}

My deepest thanks to B. Low, A. Agrawal, E. Ostrom, C. Kirchoff, and two anonymous reviewers for conversations and comments that substantially improved this manuscript. I am also grateful to all the conservation practitioners who provided the material reviewed in this study and who invest great effort in making conservation work in difficult situations.

\section{Supporting Information}

The coding scheme (Appendix S1) and a list of reviewed cases (Appendix S2) are available as part of the on-line article. The author is responsible for the content and functionality of these materials. Queries (other than absence of the material) should be directed to the corresponding author.

\section{Literature Cited}

Agrawal, A., and A. Chhatre. 2006. Explaining success on the commons: community forest governance in the Indian Himalaya. World Development 34:149-166.
Agrawal, A., and C. C. Gibson. 2001. The role of community in natural resource conservation. 1-31 in A. Agrawal and C. C. Gibson, editors. Communities and the environment: ethnicity, gender, and the State in community-based conservation. Rutgers University Press, New Brunswick, New Jersey.

Agrawal, A., and S. Goyal. 2001. Group size and collective action: thirdparty monitoring in common-pool resources. Comparative Political Studies 34:63-93.

Berkes, F. 2006. From community-based resource management to complex systems: the scale issue and marine commons. Ecology and Society 11: http://www.ecologyandsociety.org/vol11/iss1/art45/.

Berkes, F., J. Colding, and C. Folke. 2003. Navigating social-ecological systems. Cambridge University Press, Cambridge, United Kingdom.

Borgerhoff Mulder, M. 2007. Interdisciplinary collaboration: painting a brighter picture and identifying the real problem. Conservation Biology 21:903-904.

Boyd, R., and P. J. Richerson. 1992. Punishment allows the evolution of cooperation (or anything else) in sizable groups. Ethology and Sociobiology 13:171-195.

Brooks, J. S., M. A. Franzen, C. M. Holmes, M. N. Grote, and M. B. Mulder. 2006. Testing hypotheses for the success of different conservation strategies. Conservation Biology 20:1528-1538.

Bruner, A. G., R. E. Gullison, R. E. Rice, and G. Fonseca. 2001. Effectiveness of parks in protecting tropical biodiversity. Science 291:125128.

Chhatre, A., and A. Agrawal. 2008. Forest commons and local enforcement. Proceedings of the National Academy of Sciences 105:1328613291.

Costanza, R., and M. Ruth. 2001. Dynamic systems modeling. Pages 2129 in R. Costanza, B. S. Low, E. Ostrom, and J. A. Wilson, editors. Institutions, ecosystems, and sustainability. Lewis Publishers, Boca Raton, Florida.

Dobson, A., and L. Lynes. 2008. How does poaching affect the size of national parks? Trends in Ecology \& Evolution 23:177-180.

Ferraro, P. J., and S. K. Pattanayak. 2006. Money for nothing? A call for empirical evaluation of biodiversity conservation investments. Public Library of Science Biology 4:482-488.

Gibson, C. C., J. T. Williams, and E. Ostrom. 2005. Local enforcement and better forests. World Development 33:273-284.

Hayes, T., and E. Ostrom. 2005. Conserving the world's forests: are protected areas the only way? Indiana Law Review 38:595-617.

Hayes, T. M. 2006. Parks, people, and forest protection: an institutional assessment of the effectiveness of protected areas. World Development 34:2064-2075.

Hockings, M. 2003. Systems for assessing the effectiveness of management in protected areas. Bioscience 53:823-832.

Holler, M. J. 1991. Fighting pollution when decisions are strategic. Public Choice 76:347-356.

James, A., K. J. Gaston, and A. Balmford. 2001. Can we afford to conserve biodiversity? BioScience 51:43-52.

Kiyonari, T., and P. Barclay. 2008. Cooperation in social dilemmas: free riding may be thwarted by second-order reward rather than by punishment. Journal of Personality and Social Psychology 95:826842.

Leader-Williams, N., and E. J. Milner-Gulland. 1993. Policies for the enforcement of wildlife Laws: the balance between detection and penalties in Luangwa Valley, Zambia. Conservation Biology 7:611619.

Mesterton-Gibbons, M., and E. J. Milner-Gulland. 1998. On the strategic stability of monitoring: implications for cooperative wildlife management programmes in Africa. Proceedings: Biological Sciences 265:1237-1244.

Molnar, A., S. J. Scherr, and A. Khare. 2004. Who conserves the world's forests? Community-driven strategies to protect forests and respect rights. Forest Trends, Washington, D.C.

Nagendra, H. 2008. Do parks work? Impact of protected areas on land cover clearing. Ambio 37:330-336. 
Naidoo, R., A. Balmford, P. J. Ferraro, S. Polasky, T. H. Ricketts, and M. Rouget. 2006. Integrating economic costs into conservation planning. Trends in Ecology \& Evolution 21:681-687.

Oliver, P. 1980. Rewards and punishments as selective incentives for collective action: theoretical investigations. American Journal of Sociology 85:1356-1375.

Ostrom, E. 2007. A diagnostic approach for going beyond panaceas. Proceedings of the National Academy of Sciences 104:15181-15187.

Ostrom, E., R. Gardner, and J. Walker 1994. Rules, games, \& common-pool resources. University of Michigan Press, Ann Arbor, Michigan.

Ostrom, E., and H. Nagendra. 2006. Insights on linking forests, trees, and people from the air, on the ground, and in the laboratory. Proceedings of the National Academy of Sciences 103:19224-19231.

Stern, P. C., T. Dietz, N. Dolsak, E. Ostrom, and S. Stonich. 2002. Knowl- edge and questions after 15 years of research. Pages 445-486 in E. Ostrom, T. Dietz, N. Dolsak, P. C. Stern, S. Stonich, and E. U. Weber, editors. The drama of the commons. National Academy Press, Washington, D.C.

Tsebelis, G. 1989. The abuse of probability in political analysis: the Robinson Crusoe fallacy. The American Political Science Review 83:77-91.

Weissing, F. J., and E. Ostrom. 2000. Irrigation institutions and the games irrigators play: rule enforcement on government-and-farmermanaged systems. Pages 366-398 in M. D. McGinnis, editor. Polycentric Games and Institutions. University of Michigan Press, Ann Arbor, Michigan.

WWF (World Wildlife Fund). 2004. Are protected areas working? An analysis of forest protected areas by WWF. WWF International, Switzerland.

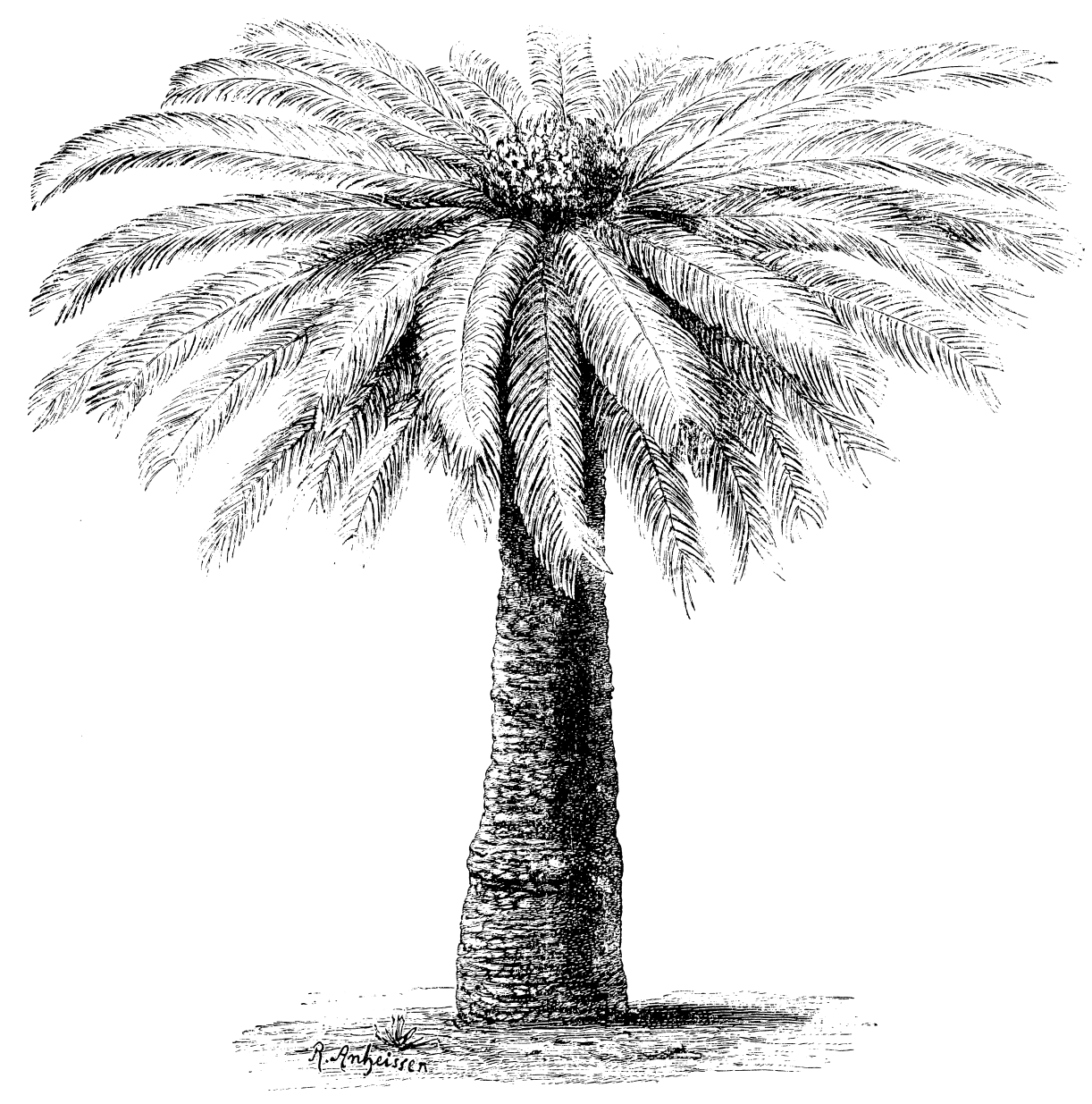

